Article

\title{
One-Dimensional Mercury Halide Coordination Polymers Based on A Semi-Rigid N-Donor Ligand: Reversible Structural Transformation
}

\author{
Pradhumna Mahat Chhetri ${ }^{1,2} \mathbb{C O}$, Xiang-Kai Yang ${ }^{1} \mathbb{C}$, Chih-Tung Yang ${ }^{1}$ and Jhy-Der Chen ${ }^{1, *}$ \\ 1 Department of Chemistry, Chung Yuan Christian University, Chung-Li 320, Taiwan; \\ mahatp@gmail.com (P.M.C.); XiangKai-Yang@outlook.com (X.-K.Y.); gm7229358@gmail.com (C.-T.Y.) \\ 2 Department of Chemistry, Amrit Science Campus, Tribhuvan University, Kathmandu 44600, Nepal \\ * Correspondence: jdchen@cycu.edu.tw; Tel.: +886-3-265-3351
}

Received: 15 February 2019; Accepted: 4 March 2019; Published: 6 March 2019

\begin{abstract}
Four one-dimensional (1D) mercury(II) halide coordination polymers have been synthesized by using a semi-rigid $N$-donor ligand, 2,2'-(1,4-phenylene)-bis( $N$-(pyridin-3-yl) acetamide) (1,4-pbpa). While $\left[\mathrm{Hg}(1,4-\mathrm{pbpa}) \mathrm{Cl}_{2} \cdot \mathrm{CH}_{3} \mathrm{OH}\right]_{\mathrm{n}}, \mathbf{1}$, forms a sinusoidal chain, the complexes $\left[\mathrm{Hg}(1,4-\mathrm{pbpa}) \mathrm{X}_{2} \ln _{\mathrm{n}}(\mathrm{X}=\mathrm{Cl}, \mathbf{2} ; \mathrm{Br}, 3 ; \mathrm{I}, 4)\right.$ are helical. The sinusoidal 1 undergoes reversible structural transformation with helical 2 upon removal and uptake of $\mathrm{CH}_{3} \mathrm{OH}$, which was accompanied with the conformation adjustment of the 1,4-pbpa ligand from trans anti-anti to trans syn-anti. Pyridyl ring rotation of the 1,4-pbpa ligand that results in the change of the ligand conformation is proposed for the initiation of the structural transformation.
\end{abstract}

Keywords: coordination polymer; bis-pyridyl-bis-amide; structural transformation; mercury halide

\section{Introduction}

The rational design and synthesis of novel coordination polymers (CPs) not only afford interesting structural topologies but also extend the range of potential applications in magnetism, luminescence, catalysis, and gas storage [1]. The preparation methods, metal-ligand ratio, and solvent combination play key roles in determining the structural diversity and properties, which can also be observed by the influence of the spacer ligands and metal identities. The structural transformations are intriguing in $\mathrm{CPs}$ due to their potential applications in switches and sensors, which can be triggered by exchange of guest molecules, removal and uptake of solvents and external stimuli like heat, light, and mechanical forces [2]. The synthesis and structures of a variety of one-dimensional (1D) mercury(II) CPs have been reported, however, it remains a challenge to elucidate their structure-ligand relationship and thereby the intrinsic properties [3-14].

We have made our effort to investigate the structural diversity and properties of the CPs constructed from the bis-pyridyl-bis-amide ligands [10] and several $\mathrm{Hg}$ (II) CPs that exhibited structural transformations have been reported $[4,5,11]$. The $\mathrm{HgI}_{2}$-containing $\mathrm{CP}\left[\mathrm{Hg}(1,2-\mathrm{pbpa}) \mathrm{I}_{2}\right]_{\mathrm{n}}$ [1,2-pbpa $=2,2^{\prime}$-(1,2-phenylene)-bis( $N$-pyridin-3-yl)acetamide] has been shown to display reversible structural transformation with $\left[\mathrm{Hg}(1,2-\mathrm{pbpa}) \mathrm{I}_{2} \cdot \mathrm{MeOH}\right]_{\mathrm{n}}$ and $\left[\mathrm{Hg}(1,2-\mathrm{pbpa}) \mathrm{I}_{2} \cdot \mathrm{MeCN}\right]_{\mathrm{n}}$ upon adsorption/desorption and exchange of methanol and acetonitrile molecules, which demonstrate the importance of $\mathrm{N}-\mathrm{H}-$ - - $\mathrm{X}(\mathrm{X}=$ halide anion $)$ and $\mathrm{Hg}-\mathrm{-}-\mathrm{X}$ interactions in the evaluation of structural transformation [4]. Moreover, reversible structural transformations between $\left[\mathrm{Hg}(1,3-\mathrm{pbpa}) \mathrm{X}_{2}\right]_{\mathrm{n}}[\mathrm{X}=\mathrm{Br}$ and I; 1,3-pbpa $=2,2^{\prime}$-(1,3-phenylene)-bis( $N$-(pyridin-3-yl)acetamide $]$ and $\left[\mathrm{Hg}(1,3-\mathrm{pbpa}) \mathrm{X}_{2} \cdot \mathrm{MeCN}\right]_{\mathrm{n}}$ were ascribed to the formation and breaking of the $\mathrm{N}-\mathrm{H}-\mathrm{-}-\mathrm{N}$ hydrogen bonds to the acetonitrile molecules [5]. Although several $\mathrm{HgCl}_{2} \mathrm{CPs}$ containing the bis-pyridyl-bis-amide ligands have been 
prepared [4,5,13-15], none of them has been reported to show structural transformation upon removal and uptake of solvent. The $\mathrm{HgCl}_{2}$-containing CPs constructed from 2-(2-hydroxyethyl)pyridine have been found to proceed reversible 1D-2D structural transformation through multiple covalent bond breaking and bond reforming [11].

To investigate the effect of ligand-isomerism on the formation mercury(II) halide-containing CPs as well as the impact on the properties, we have carried out the reactions of 2,2'-(1,4-phenylene)-bis( $N$-(pyridin-3-yl)acetamide (1,4-pbpa) with the $\mathrm{Hg}(\mathrm{II})$ halide salts. Herein, we report the syntheses, structures and emission properties of the $1 \mathrm{D} \mathrm{CPs}\left[\mathrm{Hg}(1,4-\mathrm{pbpa}) \mathrm{Cl}_{2} \cdot \mathrm{CH}_{3} \mathrm{OH}\right]_{\mathrm{n}}, 1$, and $\left[\mathrm{Hg}(1,4-\mathrm{pbpa}) \mathrm{X}_{2}\right]_{\mathrm{n}}(\mathrm{X}=\mathrm{Cl}, 2 ; \mathrm{Br}, 3 ; \mathrm{I}, 4)$. Reversible structural transformation between sinusoidal 1 with the trans anti-anti ligand conformation and helical 2 with the trans syn-anti conformation upon removal and uptake of $\mathrm{CH}_{3} \mathrm{OH}$ is reported. The factors that govern the reversible structural transformation are also discussed.

\section{Experimental Section}

\subsection{General Procedures}

The elemental analyses $(\mathrm{C}, \mathrm{H}$, and $\mathrm{N}$ ) were performed using a PE 2400 series II CHNS/O (PerkinElmer Instruments, Shelton, CT, USA) or an Elementar Vario EL-III analyzer (Elementar Analysensysteme $\mathrm{GmbH}$, Hanau, German). The IR spectra (KBr disk) were recorded on a JASCO FT/IR-460 plus spectrometer ((JASCO, Easton, MD, USA). The powder X-ray diffraction was carried out by using a Bruker D2 PHASER diffractometer (Bruker Corporation, Karlsruhe, Germany) equipped with a $\mathrm{CuK}_{\alpha}(\lambda=1.54 \AA)$ radiation. The solid state emission spectroscopy was done using a Hitachi F-4500 spectrometer (Hitachi, Tokyo, Japan) with excitation slit $=5.0 \mathrm{~nm}$ and emission slit $=5.0 \mathrm{~nm}$ at room temperature.

\subsection{Materials}

The reagents 1,4-phenylenediacetic acid was purchased from ACROS Co. (Pittsburgh, PA, USA), and 3-aminopyridine, pyridine, tripenylphosphite, and mercury(II) halide salts from Alfa Aesar Co. (Heysham, UK). The ligand 2,2'-(1,4-phenylene)-bis(N-(pyridin-3-yl)acetamide) (1,4-pbpa) was prepared according to a published procedure [16].

\subsection{Preparations}

\subsection{1. $\left[\mathrm{Hg}(1,4-\mathrm{pbpa}) \mathrm{Cl}_{2} \cdot \mathrm{CH}_{3} \mathrm{OH}\right]_{\mathrm{n}}, 1$}

A $20 \mathrm{~mL} \mathrm{MeOH}$ solution of $\mathrm{HgCl}_{2}(0.054 \mathrm{~g}, 0.20 \mathrm{mmol})$ was layered on top of a $20 \mathrm{~mL} \mathrm{THF}$ solution of 1,4-pbpa $(0.069 \mathrm{~g}, 0.20 \mathrm{mmol})$. After two weeks, colorless crystals of 1 were generated, which were then collected. Yield: $0.032 \mathrm{~g}(25 \%)$. Anal. calcd for $\mathrm{C}_{21} \mathrm{H}_{22} \mathrm{Cl}_{2} \mathrm{HgN}_{4} \mathrm{O}_{3}\left(M_{W}=649.91\right)$ : C, 38.81; N, 8.62; H, 3.41\%. Found: C, 38.48; N, 8.94; H, 2.91\%. IR (cm $\left.{ }^{-1}\right): 560(\mathrm{w}), 639(\mathrm{w}), 701(\mathrm{~m})$, 735(w), 781(w), 812(m), 968(w), 1026(w), 1047(w), 1105(w), 1148(m), 1196(m), 1244(w), 1300(m), 1345(s), 1427(s), 1478(s), 1540(s), 1593(m), 1675(s, C=O), 2918(w), 3030(w), 3063(w), 3131(w), 3190(w), 3303(w, $\mathrm{N}-\mathrm{H}$ stretch).

\subsection{2. $\left[\mathrm{Hg}(1,4-\mathrm{pbpa}) \mathrm{Cl}_{2}\right]_{\mathrm{n}}, 2$}

Compound 2 was prepared by following the procedure described for 1, except a $20 \mathrm{~mL} \mathrm{EtOH}$ solution of $\mathrm{HgCl}_{2}$ was used. Yield: $0.030 \mathrm{~g}(20 \%)$. Anal. calcd for $\mathrm{C}_{20} \mathrm{H}_{18} \mathrm{Cl}_{2} \mathrm{HgN}_{4} \mathrm{O}_{2}\left(M_{W}=617.87\right)$ : C, 38.88; N, 9.07; H, 2.94\%. Found: C, 38.95; N, 9.03; H, 2.85\%. IR (cm $\left.{ }^{-1}\right): 416(\mathrm{w}), 504(\mathrm{~m}), 557(\mathrm{~m}), 592(\mathrm{~m})$, 636(m), 701(s), 739(m), 782(m), 811(s), 864(w), 923(w), 961(w), 1023(w), 1051(m), 1108(m), 1149(s), 1204(m), 1248(m), 1274(s), 1299(m), 1353(s), 1428(s), 1480(s), 1548(s), 1587(s), 1673(s, C=O), 2921(w), 3075(w), 3134(m), 3269(s, N-H stretch), 3358(s, N-H stretch). 


\subsection{3. $\left[\mathrm{Hg}(1,4-\mathrm{pbpa}) \mathrm{Br}_{2}\right]_{\mathrm{n}}, 3$}

A $20 \mathrm{~mL} \mathrm{MeOH}$ or EtOH solution of $\mathrm{HgBr}_{2}(0.072 \mathrm{~g}, 0.20 \mathrm{mmol})$ was layered on top of a $20 \mathrm{~mL}$ THF solution of 1,4-pbpa ( $0.069 \mathrm{~g}, 0.20 \mathrm{mmol})$. After two weeks, colorless crystals of 3 were generated, which were then collected. Yield: $0.047 \mathrm{~g}(33 \%)$. Anal. calcd for $\mathrm{C}_{20} \mathrm{H}_{18} \mathrm{Br}_{2} \mathrm{HgN}_{4} \mathrm{O}_{2}\left(M_{W}=706.79\right)$ : $\mathrm{C}$, 33.99; N, 7.93; H, 2.57\%. Found: C, 34.36; N, 7.79; H, 2.22\%. IR ( $\left.\mathrm{cm}^{-1}\right): 416(\mathrm{w}), 504(\mathrm{~m}), 557(\mathrm{~m}), 592(\mathrm{~m})$, 636(m), 701(s), 739(m), 782(m), 811(s), 864(w), 923(w), 961(w), 1023(w), 1051(m), 1108(m), 1149(s), 1204(m), 1248(m), 1274(s), 1299(m), 1344(s), 1428(s), 1480(s), 1546(s), 1586(s), 1672(s, C=O), 2921(w), 3075(w), 3134(m) , 3262(s, N-H stretch), 3358(s, N-H stretch).

\subsection{4. $\left[\operatorname{Hg}(1,4-\mathrm{pbpa}) \mathrm{I}_{2}\right]_{\mathrm{n}}, 4$}

Compound 4 was prepared by following the procedure described for 3, except $\mathrm{HgI}_{2}(0.091 \mathrm{~g}$, $0.20 \mathrm{mmol})$ was used. Yield: $0.061 \mathrm{~g}(38 \%)$. Anal. calcd for $\mathrm{C}_{20} \mathrm{H}_{18} \mathrm{HgI}_{2} \mathrm{~N}_{4} \mathrm{O}_{2}\left(M_{W}=800.77\right): \mathrm{C}, 29.99$; $\mathrm{N}, 6.99 ; \mathrm{H}, 2.27 \%$. Found: C, 30.46; N, 6.95; H, 2.4\%. IR ( $\left.\mathrm{cm}^{-1}\right): 416(\mathrm{w}), 504(\mathrm{~m}), 557(\mathrm{~m}), 592(\mathrm{~m}), 636(\mathrm{~m})$, 701(s), 739(m), 782(m), 811(s), 864(w), 923(w), 961(w), 1023(w), 1051(m), 1108(m), 1149(s), 1204(m), 1248(m), 1274(s), 1299(m), 1342(s), 1427(s), 1478(s), 1546(s), 1586(s), 1670(s, C=O), 2921(w), 3075(w), 3134(m) , 3250(s, N-H stretch), 3355(s, N-H stretch).

The purities of complexes 1-4 have been examined by using the PXRD patterns, Figures S1-S4.

\subsection{X-ray Crystallography}

A Bruker AXS SMART APEX II CCD diffractometer (Bruker AXS, Madison, WI, USA) that was equipped with a graphite monochromated $\operatorname{MoK} \alpha(\lambda=0.71073 \AA)$ radiation and operated at $50 \mathrm{kV}$ and $30 \mathrm{~mA}$ was used to collect the diffraction data for complexes 1-4. Data reduction was performed by using well-established computational procedures with empirical absorption correction based on "multi-scan" [17]. Patterson or direct method was used to locate the positions of some of the heavier atoms and the remaining atoms were found in a series of alternating difference Fourier maps and least-square refinements, while hydrogen atoms were added by using the HADD command in SHELXTL [18]. The $\mathrm{CH}_{3} \mathrm{OH}$ molecule of $\mathbf{1}$ is disordered such that two sets of orientations of the oxygen atom can be shown. Basic crystal parameters and structure refinement are summarized in Table 1.

Table 1. Crystal data for complexes 1-4.

\begin{tabular}{|c|c|c|c|c|}
\hline Compound & 1 & 2 & 3 & 4 \\
\hline $\begin{array}{l}\text { Formula } \\
\text { FW }\end{array}$ & $\begin{array}{c}\mathrm{C}_{21} \mathrm{H}_{22} \mathrm{Cl}_{2} \mathrm{HgN}_{4} \mathrm{O}_{3} \\
649.91\end{array}$ & $\begin{array}{c}\mathrm{C}_{20} \mathrm{H}_{18} \mathrm{Cl}_{2} \mathrm{HgN}_{4} \mathrm{O}_{2} \\
617.87\end{array}$ & $\begin{array}{c}\mathrm{C}_{20} \mathrm{H}_{18} \mathrm{Br}_{2} \mathrm{HgN}_{4} \mathrm{O}_{2} \\
706.79\end{array}$ & $\begin{array}{c}\mathrm{C}_{20} \mathrm{H}_{18} \mathrm{HgI}_{2} \mathrm{~N}_{4} \mathrm{O}_{2} \\
800.77\end{array}$ \\
\hline Crystal System & Monoclinic & Monoclinic & Monoclinic & Monoclinic \\
\hline Space Group & $\mathrm{P} 2{ }_{1} / \mathrm{m}$ & $\mathrm{P} 2{ }_{1} / \mathrm{c}$ & $\mathrm{P} 22_{1} / \mathrm{c}$ & $\mathrm{P} 2_{1} / \mathrm{c}$ \\
\hline $\mathrm{a}, \AA$ & $5.0705(1)$ & $9.3764(5)$ & $9.3217(1)$ & $9.3679(2)$ \\
\hline $\mathrm{b}, \AA$ & $20.6636(5)$ & $13.3232(7)$ & $13.4660(1)$ & $13.6718(3)$ \\
\hline c, $\AA$ & $11.4320(3)$ & $17.1229(10)$ & $17.2458(2)$ & $17.3825(5)$ \\
\hline$\alpha^{\circ}$ & 90 & 90 & 90 & 90 \\
\hline$\beta,{ }^{\circ}$ & $92.3088(18)$ & $97.490(2)$ & $96.741(1)$ & $95.555(1)$ \\
\hline$\gamma,{ }^{\circ}$ & 90 & 90 & 90 & 90 \\
\hline $\mathrm{V}, \AA^{3}$ & 1196.81(5) & $2120.8(2)$ & $2149.83(4)$ & 2215.83(9) \\
\hline Temperature, $\mathrm{K}$ & $296(2)$ & $299(2)$ & $296(2)$ & $296(2)$ \\
\hline Dcal, $\mathrm{g} \mathrm{cm}^{-3}$ & 1.803 & 1.935 & 2.184 & 2.400 \\
\hline $\mathrm{F}(000)$ & 628 & 1184 & 1328 & 1472 \\
\hline $\mathrm{Z}$ & 2 & 4 & 4 & 4 \\
\hline$\mu(\mathrm{Mo} \mathrm{K} \alpha), \mathrm{mm}^{-1}$ & 6.682 & 7.533 & 10.9 & 9.756 \\
\hline $\begin{array}{l}\text { Range }(2 \theta) \text { for data } \\
\text { collection, }{ }^{\circ}\end{array}$ & 4.07 to 56.74 & 3.88 to 56.63 & 3.84 to 56.60 & 3.79 to 56.68 \\
\hline Reflections collected & 11011 & 19495 & 21154 & 20206 \\
\hline
\end{tabular}


Table 1. Cont.

\begin{tabular}{|c|c|c|c|c|}
\hline Compound & 1 & 2 & 3 & 4 \\
\hline Independent reflections & $\begin{array}{c}3057 \\
{[\mathrm{R}(\mathrm{int})=0.0491]}\end{array}$ & $\begin{array}{c}5275 \\
{[\mathrm{R}(\mathrm{int})=0.0260]}\end{array}$ & $\begin{array}{c}5335 \\
{[\mathrm{R}(\mathrm{int})=0.0353]}\end{array}$ & $\begin{array}{c}5516 \\
{[R(\text { int })=0.0323]}\end{array}$ \\
\hline Data/restraints/parameters & $3057 / 1 / 143$ & $5275 / 0 / 262$ & $5335 / 0 / 262$ & $5516 / 0 / 262$ \\
\hline $\begin{array}{l}\text { Quality-of-fit } \\
\text { Indicator }\end{array}$ & 1.009 & 1.032 & 1.022 & 1.022 \\
\hline $\begin{array}{l}\text { Final } R \text { indices } \\
{[I>2 \sigma(\mathrm{I})]^{\mathrm{a}, \mathrm{b}}} \\
\mathrm{R} \text { indices } \\
\text { (all data) }\end{array}$ & $\begin{array}{r}\mathrm{R} 1=0.0364 \\
\mathrm{wR} 2=0.0711 \\
\mathrm{R} 1=0.0558 \\
\mathrm{wR} 2=0.0783\end{array}$ & $\begin{array}{r}\mathrm{R} 1=0.0255 \\
\mathrm{wR} 2=0.0492 \\
\mathrm{R} 1=0.0379 \\
\mathrm{wR} 2=0.0524\end{array}$ & $\begin{array}{c}\mathrm{R} 1=0.0312, \\
\mathrm{wR} 2=0.0556 \\
\mathrm{R} 1=0.0537, \\
\mathrm{wR} 2=0.0608\end{array}$ & $\begin{array}{r}\mathrm{R} 1=0.0337 \\
\mathrm{w} 22=0.0840 \\
\mathrm{R} 1=0.0421 \\
\mathrm{w} 22=0.0882\end{array}$ \\
\hline
\end{tabular}

\section{Results and Discussion}

\subsection{Synthesis}

Complexes 1-4 were prepared by layering the $\mathrm{MeOH}$ or EtOH solution of mercury(II) halide on top of the THF solution of 1,4-pbpa. Using the combination of $\mathrm{MeOH}$ and THF solvents, the reaction of $\mathrm{HgCl}_{2}$ with 1,4-pbpa afforded the sinusoidal 1 containing the co-crystallized $\mathrm{MeOH}$ molecule, while that of EtOH and THF gave helical 2 without solvent co-crystallization. However, either in $\mathrm{MeOH}$ or $\mathrm{EtOH}$, reactions of $\mathrm{HgBr}_{2}$ and $\mathrm{HgI}_{2}$ with 1,4-pbpa gave 3 and 4, respectively, without solvent co-crystallization. The powder patterns of helical 3 and 4 prepared from $\mathrm{HgBr}_{2}$ and $\mathrm{HgI}_{2}$ in $\mathrm{MeOH} / \mathrm{THF}$ and EtOH/THF are shown in Figures S3 and S4, respectively, which indicate that formation of 3 and 4 is irrespective of the solvent system. Scheme 1 depicts the synthetic pathways for $1-4$.

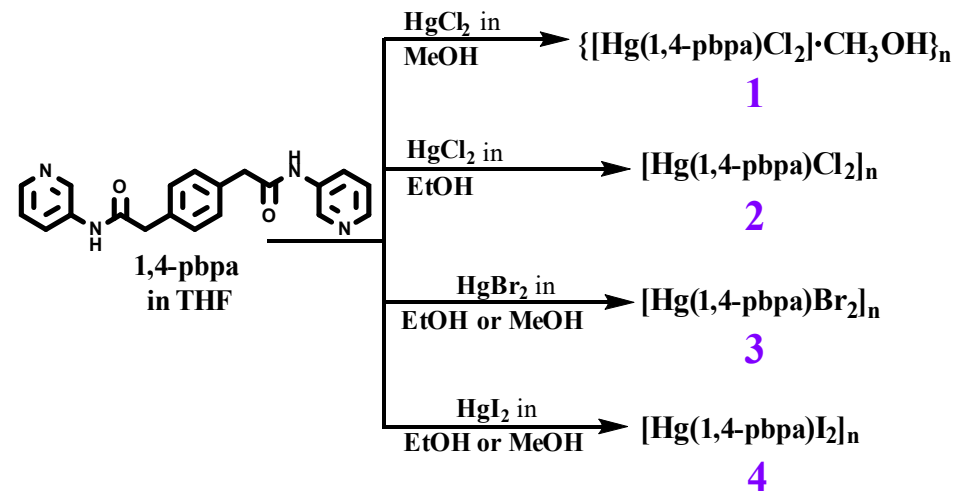

Scheme 1. Synthetic pathways for complexes 1-4.

\subsection{Structural Descriptions}

\subsubsection{Structure of $\mathbf{1}$}

Single-crystal X-ray structural analysis shows that the crystals of $\mathbf{1}$ conform to the monoclinic space group $P 2_{1} / m$ with a half of $\mathrm{Hg}$ (II) ion, a half of 1,4-pbpa ligand, two halves of chloride anion and a half of methanol molecule in an asymmetric unit. Figure 1a depicts a drawing showing the coordination environment of metal ion, which is coordinated with two pyridyl nitrogen atoms [Hg-N $=2.432(3) \AA]$ from two 1,4-pbpa ligands and two chloride anions $[\mathrm{Hg}-\mathrm{Cl}=2.3448(19)$ and 2.3700(18) $\AA]$, resulting in a distorted tetrahedral geometry $\left(\tau_{4}=0.75\right)[19,20]$. The 1,4-pbpa ligands bridge the adjacent metal ions to form a 1D sinusoidal chain, Figure $1 \mathrm{~b}$. The repeating unit reveals the period of $20.66 \AA$ involving two 1,4-pbpa ligands and two $\mathrm{Hg}(\mathrm{II})$ ions, which is slightly less than the Hg- - - Hg distance of $20.82 \AA$ separated by the 1,4-pbpa ligand, while the amplitude of the sinusoidal chain is 
$9.04 \AA$. The dihedral angle of pyridine-pyridine ring is $0^{\circ}$ and that of benzene-pyridine ring is $69.44^{\circ}$. Two-dimensional supramolecular structure is stabilized by N-H- - -O [H- - -O = 2.16 $\AA$; N- - -O = 2.96 $\left.\AA ; \angle \mathrm{N}-\mathrm{H}-\mathrm{-}-\mathrm{O}=153.2^{\circ}\right]$ hydrogen bonding originating from the amide hydrogen atoms to the amide oxygen atoms in the adjacent chains, as shown in Figure 1c. Figure 1d reveals that these interlinked chains stacked along the $a$ axis and the methanol molecules are located in the concave-convex sites, which interact with the methylene hydrogen atoms of 1,4-pbpa ligands through weak $\mathrm{C}-\mathrm{H}-\mathrm{-}-\mathrm{O}$ hydrogen bonds ( $\mathrm{H}-\mathrm{-}-\mathrm{O}=3.14 \AA$; C - - $-\mathrm{O}=3.98 \AA$; $\angle \mathrm{C}-\mathrm{H}-\mathrm{-}-\mathrm{O}=146.6^{\circ}$ ) [21].

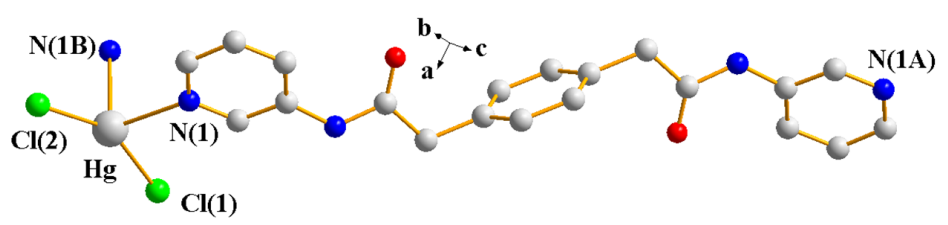

$(\mathbf{a})$

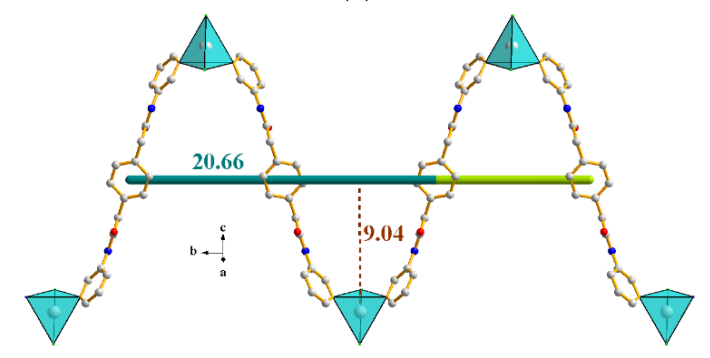

(b)

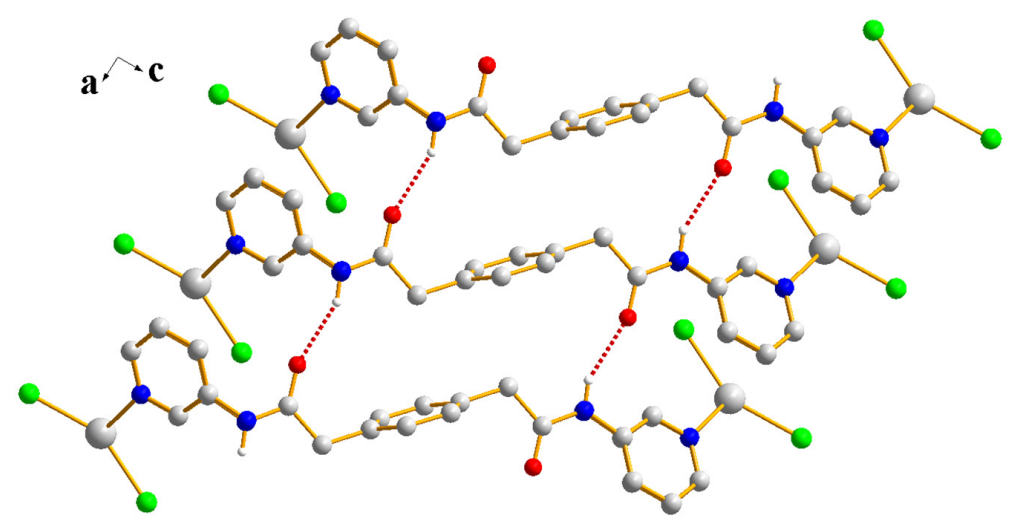

(c)

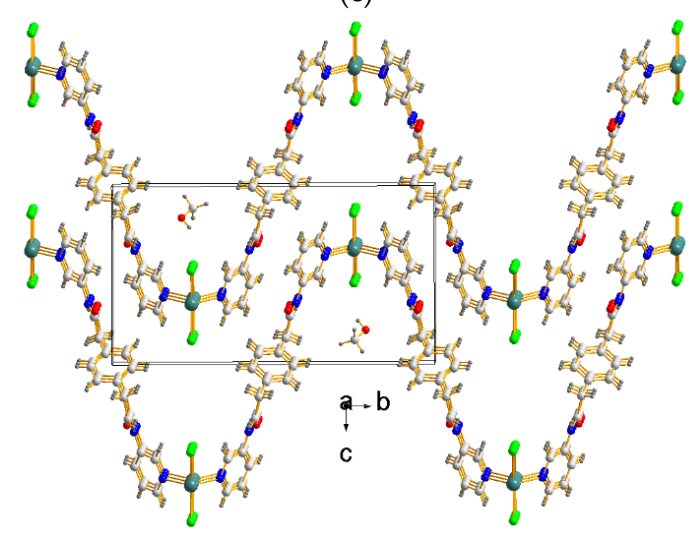

(d)

Figure 1. (a) A representative drawing showing coordination environment about the $\mathrm{Hg}$ (II) ion for 1. Symmetry transformations used to generate equivalent atoms: (A) $x,-y+3 / 2$, z. (b) A drawing showing the 1D sinusoidal chain. (c) A drawing showing the $\mathrm{N}-\mathrm{H}---\mathrm{O}$ (red dash) hydrogen bonds. (d) A view looking down the $a$ axis. 


\subsubsection{Structures of $\mathbf{2}-\mathbf{4}$}

Single crystal X-ray structural analyses revealed that isomorphous crystals of 2-4 conform to the monoclinic space group $P 2_{1} / c$ with one $\mathrm{Hg}$ (II) ion, one 1,4-pbpa ligand and two halide anions in an asymmetric unit. Figure $2 \mathrm{a}$ depicts a representative drawing showing the coordination environment of the metal ion, which is coordinated with two halide ions $[\mathrm{Hg}-\mathrm{X}=2.3552(1)$ and 2.3581(9) $\AA$ for 2; 2.4805(5) and 2.4846(5) $\AA$ for 3; 2.6488(5) and 2.6462(5) $\AA$ for 4] and two pyridyl nitrogen atoms [Hg-N $=2.415(2)$ and 2.452(2) $\AA$ for $2 ; 2.404(3)$ and 2.455(3) $\AA$ for 3; 2.416(5) and 2.477(5) $\AA$ for 4] from two 1,4 -pbpa ligands, resulting in a distorted tetrahedral geometry $\left(\tau_{4}=0.74,2 ; 0.75,3 ; 0.77,4\right)$. Complexes 2-4 form 1D helical chains having the period of $16.29,16.38$ and $16.57 \AA$, respectively, involving one 1,4-pbpa ligand and two $\mathrm{Hg}(\mathrm{II})$ cations, Figure $2 \mathrm{~b}$. The $1 \mathrm{D}$ helical chains are supported by the $\mathrm{N}-\mathrm{H}-\mathrm{-}-\mathrm{O}\left[\mathrm{H}-\mathrm{-}-\mathrm{O}=2.11 \AA \AA \mathrm{A}-\mathrm{N}-\mathrm{O}=2.86 \AA\right.$; $\angle \mathrm{N}-\mathrm{H}-\mathrm{-}-\mathrm{O}=144.3^{\circ}, 2 ; \mathrm{H}-\mathrm{-}-\mathrm{O}=2.10 \AA$ $; \mathrm{N}-\mathrm{-}-\mathrm{O}=2.83 \AA$; $\angle \mathrm{N}-\mathrm{H}-\mathrm{-}-\mathrm{O}=142.2^{\circ}, 3 ;\left[\mathrm{H}---\mathrm{O}=2.07 \AA ; \mathrm{N}---\mathrm{O}=2.80 \AA ; \angle \mathrm{N}-\mathrm{H}---\mathrm{O}=142.2^{\circ}, 4\right]$ hydrogen bonds originating from the amide groups in 1,4-pbpa and forming $2 \mathrm{D}$ supramolecular structures in a crossover fashion, as shown in Figure 2c.

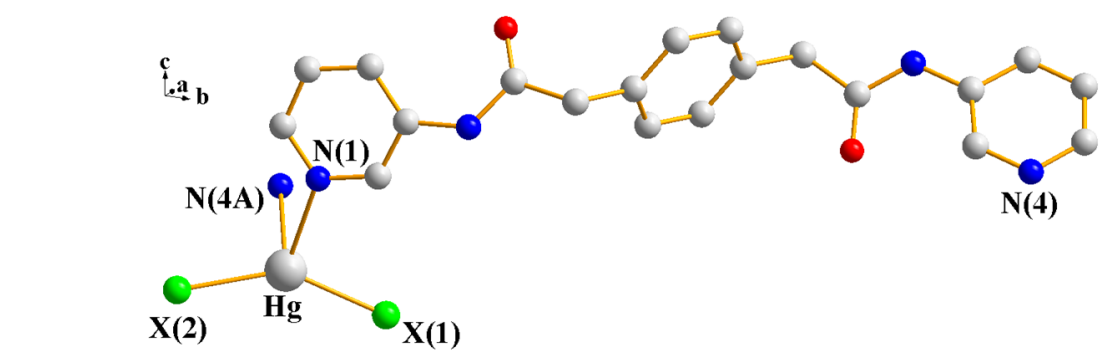

(a)

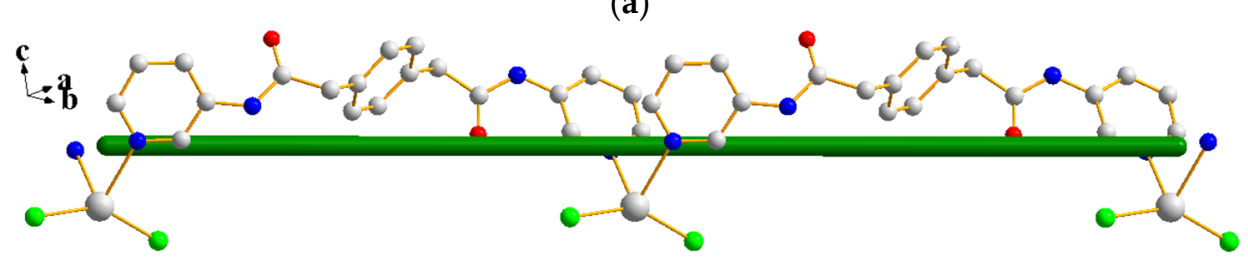

(b)

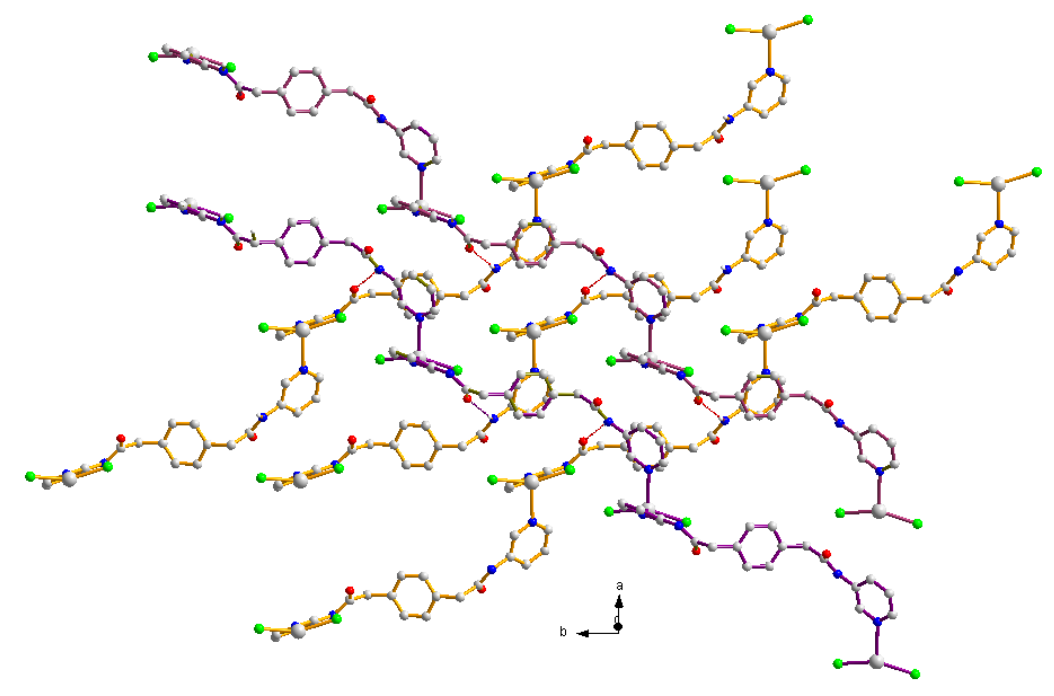

(c)

Figure 2. (a) A representative drawing showing coordination environment about the $\mathrm{Hg}$ (II) ion for 2-4. Symmetry transformations used to generate equivalent atoms: (A) $x-1, y-1, z$. (b) A representative drawing showing the $1 \mathrm{D}$ helical chain for 2-4. (c) A drawing showing the $\mathrm{N}-\mathrm{H}-\mathbf{-}-\mathrm{O}$ (red dash) hydrogen bonds that link the chains in a crossover fashion. 


\subsubsection{Ligand Conformation}

The conformation of bis-pyridine-bis-amide has been determined by the orientations of $\mathrm{C}=\mathrm{O}$ or $\mathrm{N}-\mathrm{H}$ pairs and the orientations of the pyridyl nitrogen and amide oxygen. If the orientation of $\mathrm{C}=\mathrm{O}$ or $\mathrm{N}-\mathrm{H}$ pair are on the same direction, it is defined as "cis", and if the pair is on the opposite direction, it is defined as "trans". By considering the orientations of pyridyl nitrogen and amide oxygen, syn-syn, anti-anti and syn-anti are also specified [10,22,23]. Accordingly, the conformations of 1,4-pbpa are trans anti-anti in $\mathbf{1}$, Scheme $2 a$, and trans syn-anti in 2-4, Scheme $2 b$, indicating that the co-crystallized solvents play important role in determining the ligand conformation and, thus, the structural type. The detail of dihedral angles and conformations of 1,4-pbpa in 1-4 are listed in Table 2.

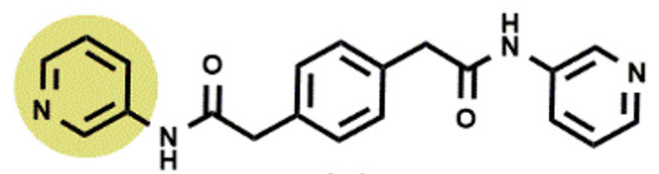

(a)

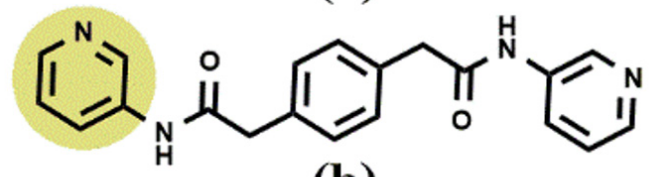

(b)

Scheme 2. Ligand conformations in complexes 1-4. (a) trans anti-anti conformation of 1,4-pbpa in 1 and (b) trans syn-anti conformation of 1,4-pbpa in $\mathbf{2}-\mathbf{4}$.

Table 2. Selected parameters for complexes 1 and 2.

\begin{tabular}{|c|c|c|c|c|c|c|}
\hline \multirow{2}{*}{ Complex } & \multicolumn{4}{|c|}{ Dihedral Angle ${ }^{\circ}$} & \multirow{2}{*}{ Conformation } & \multirow{2}{*}{ Structure } \\
\hline & Py-Py & Ph-Py & Py-NCO & NCO-NCO & & \\
\hline 1 & 0 & 69.4 & 28.4 & 0 & trans anti-anti & sinusoidal \\
\hline 2 & 48.4 & $57.0,81.6$ & $32.6,22.7$ & 8.6 & trans syn-anti & helical \\
\hline
\end{tabular}

\subsubsection{Structural Comparisons}

The structural difference between sinusoidal $\mathbf{1}$ and helical $\mathbf{2}$ implies the influence of the cocrystallized $\mathrm{MeOH}$ solvent molecules on the structural diversity of the mercury(II) chloride CPs constructed from 1,4-pbpa ligands. A comparison of the structures of 2-4 indicates that the identity of the halide anions shows no effect on the structural type of the $\mathrm{Hg}$ (II) halide CPs based on 1,4-pbpa.

It is worthwhile to investigate the isomeric effect of 1,2-, 1,3-, and 1,4-pbpa ligands on the structural diversity of the $\mathrm{Hg}$ (II) halide CPs, Table 3. Solvothermal reactions of $\mathrm{HgX}_{2}$ with 1,2-pbpa in ethanol afforded the isostructural $1 \mathrm{D}$ zigzag chains $\left[\mathrm{Hg}(1,2-\mathrm{pbpa}) \mathrm{X}_{2}\right]_{\mathrm{n}}(\mathrm{X}=\mathrm{Cl}, \mathrm{Br}$ and I), while layering reactions of a ethanolic solution of 1,2-pbpa with a methanolic solution and an acetonitrile solution of $\mathrm{HgI}_{2}$ gave $1 \mathrm{D}$ helical chains $\left[\mathrm{Hg}(1,2-\mathrm{pbpa}) \mathrm{I}_{2} \cdot \mathrm{MeOH}\right]_{n}$ and $\left[\mathrm{Hg}(1,2-\mathrm{pbpa}) \mathrm{I}_{2} \cdot \mathrm{MeCN}\right]_{n}$, respectively [4]. On the other hand, solvothermal reactions of $\mathrm{HgX}_{2}$ salts with 1,3-pbpa in acetonitrile afforded the $1 \mathrm{D}$ helical chains $\left[\mathrm{Hg}(1,3-\mathrm{pbpa}) \mathrm{X}_{2}\right]_{\mathrm{n}}(\mathrm{X}=\mathrm{Cl}, \mathrm{Br}$ and $\mathrm{I})$, and the $1 \mathrm{D}$ mesohelical chains $\left[\mathrm{Hg}(1,3-\mathrm{pbpa}) \mathrm{X}_{2} \cdot \mathrm{MeCN}\right]_{\mathrm{n}}(\mathrm{X}=\mathrm{Br}$ and $\mathrm{I})$ were obtained by layering solutions of $\mathrm{Hg} \mathrm{X}_{2}$ and 1,3-pbpa at room temperature [5]. For those complexes without co-crystallized solvents, the 1,3-pbpa and 1,4-pbpa ligands direct the same structural type of helical chain, which are in marked contrast to the 1,2-pbpa ligands that result in the zigzag chain. Moreover, structural variations are observed upon solvent co-crystallization, leading to the formation of helical chains, mesohelical chains, and sinusoidal chain for the $\mathrm{Hg}$ (II) CPs constructed from, 1,2-pbpa, 1,3-pbpa and 1,4-pbpa, respectively. The structural diversity of these pbpa-based $\mathrm{Hg}$ (II) halide CPs are thus most probably governed by the co-crystallized solvent molecules and ligand-isomerism of the pbpa ligands, whereas the role of the halide anions is not influential. 
Table 3. Structural diversity of these pbpa-based $\mathrm{Hg}(\mathrm{II})$ halide CPs.

\begin{tabular}{ccc}
\hline Complex & Structure & Reference \\
\hline$\left[\mathrm{Hg}(1,2-\mathrm{pbpa}) \mathrm{Cl}_{2}\right]_{\mathrm{n}}$ & Zigzag chain & {$[4]$} \\
{$\left[\mathrm{Hg}(1,2-\mathrm{pbpa}) \mathrm{Br}_{2}\right]_{\mathrm{n}}$} & Zigzag chain & {$[4]$} \\
{$\left[\mathrm{Hg}(1,2-\mathrm{pbpa}) \mathrm{I}_{2}\right]_{\mathrm{n}}$} & Zigzag chain & {$[4]$} \\
$\left\{\left[\mathrm{Hg}(1,2-\mathrm{pbpa}) \mathrm{I}_{2}\right] \cdot \mathrm{MeCN}\right\}_{\mathrm{n}}$ & Helical chain & {$[4]$} \\
$\left\{\left[\mathrm{Hg}(1,2-\mathrm{pbpa}) \mathrm{I}_{2}\right] \cdot \mathrm{MeOH}\right\}_{\mathrm{n}}$ & Helical chain & {$[4]$} \\
{$\left[\mathrm{Hg}(1,3-\mathrm{pbpa}) \mathrm{Cl}_{2}\right]_{\mathrm{n}}$} & Helical chain & {$[5]$} \\
{$\left[\mathrm{Hg}(1,3-\mathrm{pbpa}) \mathrm{Br}_{2}\right]_{\mathrm{n}}$} & Helical chain & {$[5]$} \\
{$\left[\mathrm{Hg}(1,3-\mathrm{pbpa}) \mathrm{I}_{2}\right]_{\mathrm{n}}$} & Helical chain & {$[5]$} \\
$\left\{\left[\mathrm{Hg}(1,3-\mathrm{pbpa}) \mathrm{Br}_{2}\right] \cdot \mathrm{MeCN}_{\mathrm{n}}\right.$ & Mesohelical chain & {$[5]$} \\
$\left\{\left[\mathrm{Hg}(1,3-\mathrm{pbpa}) \mathrm{I}_{2}\right] \cdot{\mathrm{MeCN}\}_{\mathrm{n}}}_{\left\{\left[\mathrm{Hg}(1,4-\mathrm{pbpa}) \mathrm{Cl}_{2}\right] \cdot \mathrm{MeOH}_{\mathrm{n}}, \mathbf{1}\right.}\right.$ & Mesohelical chain & {$[5]$} \\
{$\left[\mathrm{Hg}(1,4-\mathrm{pbpa}) \mathrm{Cl}_{2}\right]_{\mathrm{n}}, \mathbf{2}$} & Sinusoidal chain & This work \\
{$\left[\mathrm{Hg}(1,4-\mathrm{pbpa}) \mathrm{Br}_{2}\right]_{\mathrm{n}}, \mathbf{3}$} & Helical chain & This work \\
{$\left[\mathrm{Hg}(1,4-\mathrm{pbpa}) \mathrm{I}_{2}\right]_{\mathrm{n}}, \mathbf{4}$} & Helical chain & This work \\
\hline
\end{tabular}

\subsubsection{Structural Transformation}

The core structures of complexes $\mathbf{1}$ and $\mathbf{2}$ consist of the same formula and thus can be regarded as a pair of supramolecular isomers with and without the co-crystallized solvent molecules, which provide a unique opportunity for the study of the structural transformation between these two complexes upon removal and uptake of $\mathrm{CH}_{3} \mathrm{OH}$. To investigate the structural transformation, we first checked feasibility of the structural change from $\mathbf{1}$ to $\mathbf{2}$ by heating $\mathbf{1}$ at variable temperatures, which was verified by using powder X-ray diffraction (PXRD) patterns. When complex 1 was heated from 50 to $100{ }^{\circ} \mathrm{C}$, the PXRD patterns are significantly different from that of the simulation of $\mathbf{1}$, indicating structural transformation. Heating 1 at 120 and $150{ }^{\circ} \mathrm{C}$, respectively, afforded PXRD patterns that are comparable to that of the simulation of 2 except some peaks around $2 \theta=7.5$ and $16^{\circ}$. Moreover, increasing the temperature to $180^{\circ} \mathrm{C}$ gave a PXRD pattern well matched with the simulated pattern of 2, Figure 3 . On the other hand, immersion of 2 into $\mathrm{MeOH}$ for one month showed no significant change on the PXRD pattern, Figure S5. However, when 2 was heated solvothermally at $120^{\circ} \mathrm{C}$, the pattern changed and well matched with that of the simulation of $\mathbf{1}$, Figure 4 . To the best of our knowledge, the reversible structural transformation between $\mathbf{1}$ and $\mathbf{2}$ represents the first example of the bis-pyridyl-bis-amide-based $\mathrm{HgCl}_{2}$ $\mathrm{CPs}$. Attempts to investigate the structural transformation by immersing 3 and 4 into $\mathrm{MeOH}$, as well as heating solvothermally, led no significant change on their PXRD patterns, Figures S6-S9.

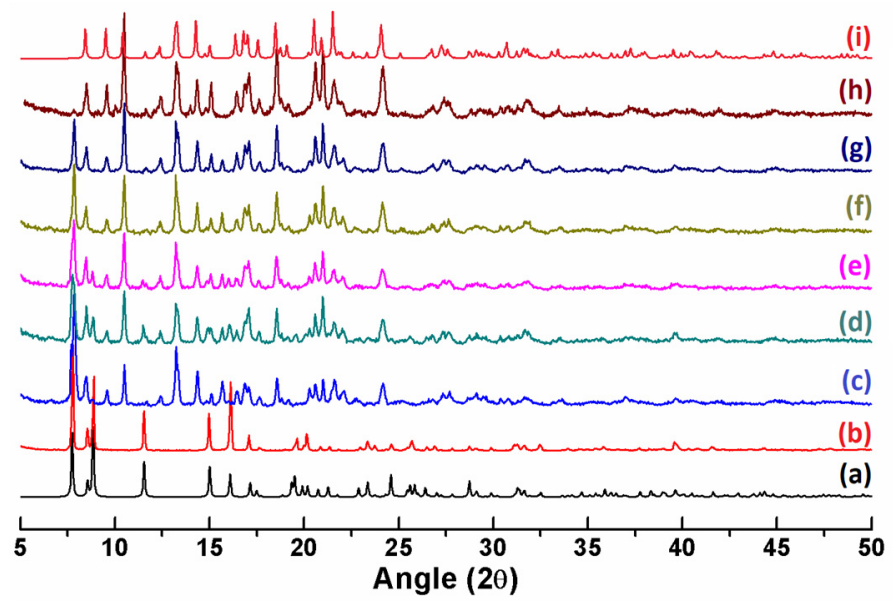

Figure 3. PXRD pattern for structural transformation from 1 to 2 . (a) Simulation of 1 ; (b) experiment of $\mathbf{1}$; (c) $\mathbf{1}$ at $50{ }^{\circ} \mathrm{C}$; (d) $\mathbf{1}$ at $70{ }^{\circ} \mathrm{C}$; (e) $\mathbf{1}$ at $100{ }^{\circ} \mathrm{C}$; (f) $\mathbf{1}$ at $120^{\circ} \mathrm{C} ;(\mathrm{g}) \mathbf{1}$ at $150{ }^{\circ} \mathrm{C}$; (h) $\mathbf{1}$ at $180{ }^{\circ} \mathrm{C}$; and (i) simulation of 2. 


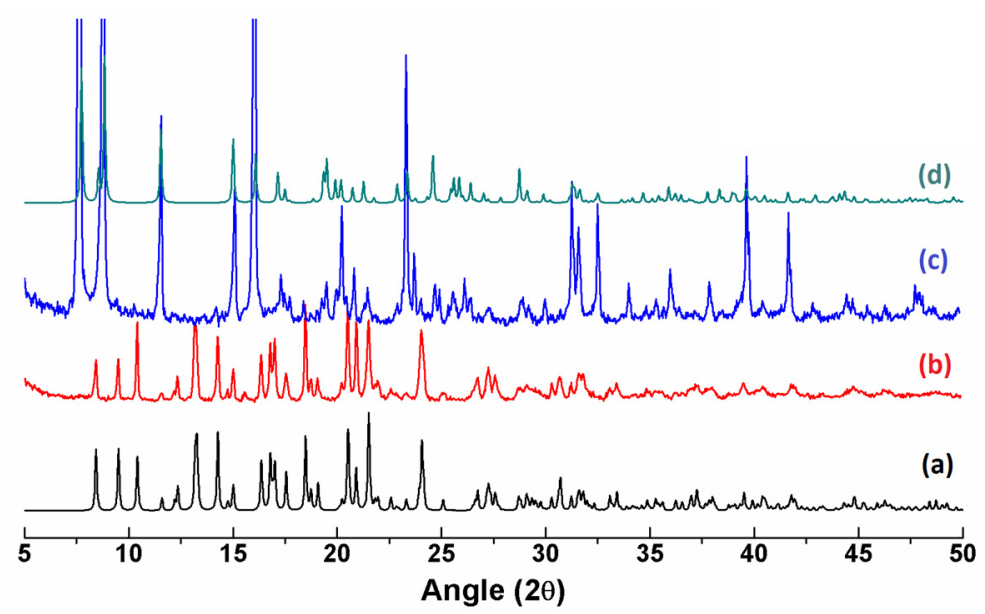

Figure 4. PXRD pattern for structural transformation from 2 to 1. (a) Simulation of 2; (b) experiment of 2; (c) 2 heated with $\mathrm{MeOH}$ at $120^{\circ} \mathrm{C}$ in hydrothermal process; and (d) simulation of $\mathbf{1}$.

To propose the possible mechanism for the structural transformation between $\mathbf{1}$ and $\mathbf{2}$, we consider the change in ligand conformation. When the sinusoidal 1 was heated to remove the $\mathrm{CH}_{3} \mathrm{OH}$ molecules, cleavage of the N-H- - -O hydrogen bonds between the stacking chains, Figure 1c, and formation of the $\mathrm{N}-\mathrm{H}-\mathrm{-}-\mathrm{O}$ hydrogen bonds between the crossover chains, Figure $2 \mathrm{c}$, result in the rearrangement of the ligand conformation from trans anti-anti to trans syn-anti and the formation of helical 2, and vice versa, when $\mathbf{2}$ was solvothermally heated in $\mathrm{CH}_{3} \mathrm{OH}$, the structure of $\mathbf{1}$ was recovered. Removal of the $\mathrm{CH}_{3} \mathrm{OH}$ from 1 thus triggers the reorientation of one of the pyridyl rings from "anti" to "syn", leading to the conversion of the conformation trans anti-anti to trans syn-anti, Scheme 3. The rotation of the pyridyl rings drastically affects the Py-Py dihedral angles from 0 to $48.4^{\circ}$ and $\mathrm{C}-\mathrm{C}-\mathrm{C}-\mathrm{O}$ torsion angles $(\theta)$ from 1.3 to 51.8 and $47.8^{\circ}$ at both sides of benzene rings and moderately modifies the Py-Ph, Py-NCO and NCO-NCO dihedral angles, Table 2. On the other hand, solvothermal reaction of 2 reversed the orientation of the pyridyl rings and recovered 1.

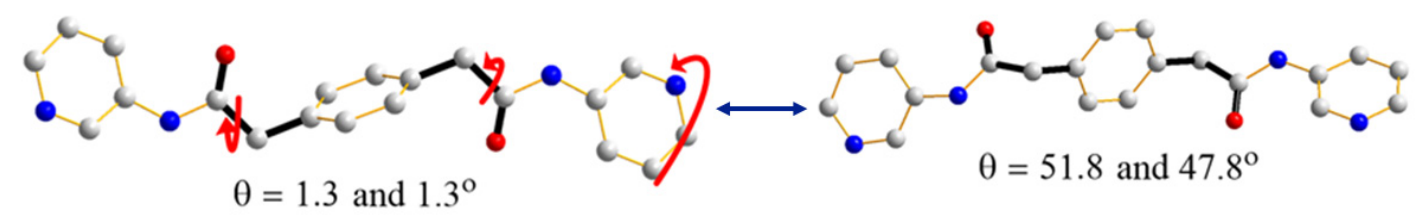

Scheme 3. Pyridyl ring rotation and torsional angle change in $\mathbf{1}$ and $\mathbf{2}$ during structural transformation.

\subsubsection{Emission Properties}

The photoluminescence (PL) property of $\mathrm{d}^{10}$ metal complexes have potential applications as chemical sensors and fluorescent materials [24-27]. The solid state PL of 1-4, and 1,4-pbpa were obtained at room temperature, Figure 5. The maximum excitation and emission wavelengths of $1-4$, and 1,4-pbpa are listed in Table 4, showing that the emissions of $\mathbf{1 - 4}$ and 1,4-pbpa appear at 448, 438, 455,461 , and $330 \mathrm{~nm}$ upon the excitations at $372,367,376,396$ and $273 \mathrm{~nm}$, respectively. Due to the $\mathrm{d}^{10}$ electronic configuration of the $\mathrm{Hg}$ (II) metal ion that undergoes hardly either oxidation or reduction, the fluorescence emissions of 1-4 may result from the organic linkers and are probably attributable to $\pi^{*} \rightarrow \mathrm{n}$ or $\pi^{*} \rightarrow \pi$ transitions [28]. The red shifts of the emission wavelengths for complexes 2-4 $\left(\mathrm{Cl}^{-}<\right.$ $\mathrm{Br}^{-}<\mathrm{I}^{-}$) may be ascribed to the different identity (electronegativity and size) of the halide anions, while coordination environment of the metal centers and arrangement of linkers also influence the luminescence [29]. 


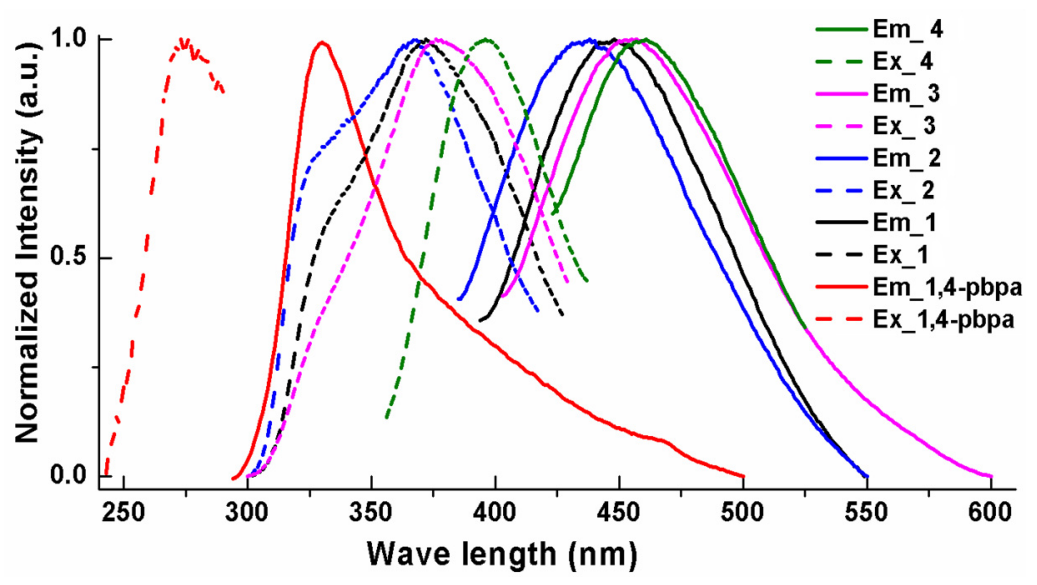

Figure 5. The solid state photoluminescence (PL) of 1-4 and 1,4-pbpa.

Table 4. Excitation and emission of complexes 1-4 and 1,4-pbpa.

\begin{tabular}{ccc}
\hline Compound & $\begin{array}{c}\text { Excitation } \\
\lambda_{\max }\end{array}$ & $\begin{array}{c}\text { Emission } \\
\lambda_{\max }\end{array}$ \\
\hline $\mathbf{1}$ & 372 & 448 \\
$\mathbf{2}$ & 367 & 438 \\
$\mathbf{3}$ & 376 & 455 \\
$\mathbf{4}$ & 396 & 461 \\
$1,4-\mathrm{pbpa}$ & 273 & 330 \\
\hline
\end{tabular}

\section{Conclusions}

Four $\mathrm{Hg}$ (II) halide CPs based on 1,4-pbpa have been synthesized and structurally characterized. While complex 1 forms a 1D sinusoidal chain, 2-4 are isostructural 1D helical chains. A comparison of the structures of the $\mathrm{Hg}$ (II) halide complexes involving 1,2-, 1,3-, and 1,4-pbpa ligands demonstrates that the co-crystallized solvent molecules and the ligand-isomerism of the spacer ligands play important roles in determining the structural diversity of the pbpa-based $\mathrm{Hg}$ (II) halide CPs, whereas the structure-directing role of the halide anion is not influential. Complex $\mathbf{1}$ undergoes reversible structural transformation with 2 upon removal and uptake of $\mathrm{CH}_{3} \mathrm{OH}$, which represents the first example of $\mathrm{HgCl}_{2}$-containing CPs constructed from the bis-pyridyl-bis-amide ligands. The structural transformation can be ascribed to the pyridyl ring rotation of the 1,4-pbpa ligand that rearranges reversibly the ligand conformation between trans anti-anti and trans syn-anti. This study provides an insight into understanding the reversibility of the structural transformation invoked by the conformational change.

Supplementary Materials: Supplementary materials can be found at http:/ / www.mdpi.com/2073-4360/11/3/ 436/s1. Crystallographic data for 1-4 have been deposited with the Cambridge Crystallographic Data Centre, CCDC no. 1891685-1891688. Figure S1. Powder X-ray patterns of 1. (a) Simulation and (b) experimental, Figure S2. Powder X-ray patterns of 2. (a) Simulation and (b) experimental; Figure S3. Powder X-ray patterns of 3. (a) Simulation (b) experimental of 3 obtained from THF/MeOH and (c) experimental of 3 obtained from THF/EtOH; Figure S4. Powder X-ray patterns of 4. (a) Simulation (b) experimental of 4 obtained from THF $/ \mathrm{MeOH}$ and (c) experimental of 4 obtained from THF/EtOH; Figure S5. Powder X-ray patterns of 2. (a) Simulation (b) experimental and (c) in $\mathrm{MeOH}$ after one month; Figure S6. Powder X-ray patterns of 3. (a) Simulation (b) experimental and (c) in $\mathrm{MeOH}$ after one month; Figure S7. Powder X-ray patterns of 3. (a) Simulation (b) experimental and (c) in solvothermal reaction with MeOH; Figure S8. Powder X-ray patterns of 4. (a) Simulation (b) experimental and (c) in MeOH after one month; Figure S9. Powder X-ray patterns of 4. (a) Simulation (b) experimental and (c) in solvothermal reaction with $\mathrm{MeOH}$.

Author Contributions: Investigation, P.M.C.; data curation, X.-K.Y.; validation, C.-T.Y.; supervision, J.-D.C.

Funding: This research was funded by Ministry of Science and Technology of the Republic of China, grant number MOST 107-2113-M-033-002. 
Acknowledgments: We are grateful to the Ministry of Science and Technology of the Republic of China for support.

Conflicts of Interest: The authors declare no conflict of interest.

\section{References}

1. Batten, S.R.; Neville, S.M.; Turner, D.R. Coordination Polymers: Design, Analysis and Application; Royal Society of Chemistry: Cambridge, UK, 2009.

2. Kole, G.K.; Vittal, J.J. Solid-state reactivity and structural transformations involving coordination polymers. Chem. Soc. Rev. 2013, 42, 1755-1775. [CrossRef] [PubMed]

3. Morsali, A.; Masoomi, M.Y. Structures and properties of mercury(II) coordination polymers. Coord. Chem. Rev. 2009, 253, 1882-1905. [CrossRef]

4. Mahat Chhetri, P.; Yang, X.-K.; Chen, J.-D. Solvent-mediated reversible structural transformation of mercury iodide coordination polymers: Role of halide anions. Cryst. Growth Des. 2017, 17, 4801-4809. [CrossRef]

5. Mahat Chhetri, P.; Yang, X.-K.; Chen, J.-D. Mercury halide coordination polymers exhibiting reversible structural transformation. CrystEngComm 2018, 20, 2126-2134. [CrossRef]

6. Mahmoudi, G.; Zaręba, J.K.; Bauzá, A.; Kubicki, M.; Bartyzel, A.; Keramidas, A.D.; Butusov, L.; Mirosławh, B.; Frontera, A. Recurrent supramolecular motifs in discrete complexes and coordination polymers based on mercury halides: Prevalence of chelate ring stacking and substituent effects. CrystEngComm 2018, 20, 1065-1076. [CrossRef]

7. Cheng, P.-C.; Yeh, C.-W.; Hsu, W.; Chen, T.-R.; Wang, H.-W.; Chen, J.-D.; Wang, J.-C. Ag(I) complexes containing flexible $N, N^{\prime}$-di(3-pyridyl)adipoamide ligands: Syntheses, structures, ligand conformations, and crystal-to-crystal transformations. Cryst. Growth Des. 2012, 12, 943-953. [CrossRef]

8. Rana, L.K.; Sharma, S.; Hundal, G. First report on crystal engineering of $\mathrm{Hg}(\mathrm{II})$ halides with fully substituted 3,4-pyridinedicarboxamides: Generation of two-dimensional coordination polymers and linear zig-zag chains of mercury metal ions. Cryst. Growth Des. 2016, 16, 92-107. [CrossRef]

9. Mahmoudi, G.; Bauzá, A.; Gurbanov, A.V.; Zubkov, F.I.; Maniukiewicz, W.; Rodriguez-Diéguez, A.; López-Torres, E.; Frontera, A. The role of unconventional stacking interactions in the supramolecular assemblies of $\mathrm{Hg}$ (II) coordination compounds. CrystEngComm 2016, 18, 9056-9066. [CrossRef]

10. Thapa, K.B.; Chen, J.-D. Crystal engineering of coordination polymers containing flexible bis-pyridyl-bis-amide ligands. CrystEngComm 2015, 17, 4611-4626. [CrossRef]

11. Thapa, K.B.; Hsu, Y.-F.; Lin, H.-C.; Chen, J.-D. Hg(II) supramolecular isomers: Structural transformation and photoluminescence change. CrystEngComm 2015, 17, 7574-7582. [CrossRef]

12. Mobin, S.M.; Srivastava, A.K.; Mathur, P.; Lahiri, G.K. Reversible single-crystal to single-crystal transformations in a $\mathrm{Hg}(\mathrm{II})$ derivative. 1D-polymeric chain $\rightleftharpoons 2 \mathrm{D}$-networking as a function of temperature. Dalton Trans. 2010, 39, 8698-8705. [CrossRef] [PubMed]

13. Burchell, T.J.; Eisler, D.J.; Puddephatt, R.J. Self-assembly using dynamic coordination chemistry and hydrogen bonding: Mercury(II) macrocycles, polymers and sheets. Inorg. Chem. 2004, 43, 5550-5557. [CrossRef] [PubMed]

14. Burchell, T.J.; Puddephatt, R.J. Self-assembly of chiral coordination polymers and macrocycles: A metal template effect on the polymer-macrocycle equilibrium. Inorg. Chem. 2005, 44, 3718-3730. [CrossRef] [PubMed]

15. Hu, H.-L.; Hsu, Y.-F.; Wu, C.-J.; Yeh, C.-W.; Chen, J.-D.; Wang, J.-C. Structural diversity in the d ${ }^{10}$ metal complexes containing $N, N^{\prime}$-di(3-pyridyl)oxamide. Polyhedron 2012, 33, 280-288. [CrossRef]

16. Maity, K.; Kundu, T.; Banerjee, R.; Biradha, K. One-dimensional water cages with repeat units of $\left(\mathrm{H}_{2} \mathrm{O}\right)_{24}$ resembling pagodane trapped in a 3D coordination polymer: Proton conduction and tunable luminescence emission by adsorption of anionic dyes. CrystEngComm 2015, 17, 4439-4443. [CrossRef]

17. Bruker AXS, APEX2, V2008.6; SAD ABS V2008/1; SAINT+ V7.60A; SHELXTL V6.14; Bruker AXS Inc.: Madison, WI, USA, 2008.

18. Sheldrick, G.M. A short history of SHELX. Acta Crystallogr. 2008, A64, 112-122. [CrossRef] [PubMed]

19. Yang, L.; Powell, D.R.; Houser, R.P. Structural variation in copper(I) complexes with pyridylmethylamide ligands: Structural analysis with a new four-coordinate geometry index, $\tau_{4}$. Dalton Trans. 2007, 9, 955-964. [CrossRef] [PubMed] 
20. Okuniewski, A.; Rosiak, D.; Chojnacki, J.; Becker, B. Coordination polymers and molecular structures among complexes of mercury(II) halides with selected 1-benzoylthioureas. Polyhedron 2015, 90, 47-57. [CrossRef]

21. Desiraju, G.R.; Steiner, T. The Weak Hydrogen Bond in Structural Chemistry and Biology; Oxford Science Publications: Oxford, UK, 2001.

22. Chang, M.-N.; Yang, X.-K.; Mahat Chhetri, P.; Chen, J.-D. Metal and ligand effects on the construction of divalent coordination polymers based on bis-pyridyl-bis-amide and polycarboxylate ligands. Polymers 2017, 9, 691. [CrossRef]

23. Thapa, K.B.; Yang, X.-K.; Chen, J.-D. Mg(II) coordination polymers based on flexible isomeric tetracarboxylate ligands: Syntheses, structures, structural transformation and luminescent properties. Polymers 2018, 10, 371. [CrossRef]

24. Kreno, L.E.; Leong, K.; Farha, O.K.; Allendorf, M.; Van Duyne, R.P.; Hupp, J.T. Metal-organic framework materials as chemical sensors. Chem. Rev. 2012, 112, 1105-1125. [CrossRef] [PubMed]

25. Cui, Y.; Yue, Y.; Qian, G.; Chen, B. Luminescent functional metal-organic frameworks. Chem. Rev. 2012, 112, 1126-1162. [CrossRef] [PubMed]

26. Sun, S.-S.; Lees, A.J. Transition metal based supramolecular systems: Synthesis, photophysics, photochemistry and their potential applications as luminescent anion chemosensors. Coord. Chem. Rev. 2002, 230, 171-192. [CrossRef]

27. Zhang, K.Y.; Yu, Q.; Wei, H.; Liu, S.; Zhao, Q.; Huang, W. Long-lived emissive probes for time-resolved photoluminescence bioimaging and biosensing. Chem. Rev. 2018, 118, 1770-1839. [CrossRef] [PubMed]

28. Allendorf, M.D.; Bauer, C.A.; Bhakta, R.K.; Houk, R.J.T. Luminescent metal-organic frameworks. Chem. Soc. Rev. 2009, 38, 1330-1352. [CrossRef] [PubMed]

29. Zeng, F.; Ni, J.; Wang, Q.; Ding, Y.; Ng, S.W.; Zhu, W.; Xie, Y. Synthesis, structures, and photoluminescence of zinc(II), cadmium(II), and mercury(II) coordination polymers constructed from two novel tetrapyridyl ligands. Cryst. Growth Des. 2010, 10, 1611-1622. [CrossRef]

(C) 2019 by the authors. Licensee MDPI, Basel, Switzerland. This article is an open access article distributed under the terms and conditions of the Creative Commons Attribution (CC BY) license (http:/ / creativecommons.org/licenses/by/4.0/). 